\title{
El amor: generador de valores
}

\author{
María Rosa Palazón
}

\begin{abstract}
Gabriela Hernández García, La plenitud vital. Ética de la conciencia amorosa en la filosofía de Joaquín Xirau. Pres. de Ramón Xirau. México, unAM, Facultad de Filosofía y Letras, División de Estudios de Posgrado, 2000. (Mirador de posgrado), 206 pp.
\end{abstract}

A las palabras de amor les sienta bien su poquito de exageración.

Antonio Machado

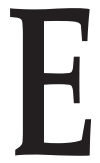

ntraron las tropas franquistas, eufemísticamente llamadas nacionales, a Barcelona. Su primer botín de guerra fue la Universitat de Barcelona. Pere Bosch Gimpera, el rector, y Joaquín Xirau i Palau, el decano de la Facultad de Filosofía y Letras, salieron al exilio. Defendían la República, o lo digno de ser defendido, según reza una carta del segundo, infatigable defensor de la autonomía universitaria y de la pedagogía que cimentó la Institución de Libre Enseñanza que encabezaron Francisco Giner de los Ríos y Manuel Bartolomé Cossío. Joaquín Xirau mantuvo una encomiable coherencia entre su teoría, su vocación magisterial y sus prácticas políticas. Es por eso que sus libros clavaron una pica en el Flandes nihilista, tecnócrata y deshumanizado siglo Xx. Declaró que llegar a México significó su resurrección. Sólo le duró seis años y medio antes del trágico accidente que cegó su vida. Dos de sus libros Amor y mundo ${ }^{1}$ y Pedagogía $i$ vida ${ }^{2}$ dejaron en mí una huella

${ }^{1}$ Joaquín Xirau, Obras. Amor y mundo, Lo fugaz y lo eterno, Vida y obras de Ramón Llull. México, Facultad de Filosofía y Letras, UNAM, 1963. Sobre este tema escribí "Amor versus fascismo (Joaquín y Ramón Xirau)", en Cincuenta años de exilio español en México. Tlaxcala, Embajada de España en México/Universidad Autónoma de Tlaxcala, 1991 (Materiales para la historia de la filosofía en México).

${ }^{2}$ J. Xirau, Pedagogía i vida. Introd. i tria de textos Miquel Siguan i Soler. Vic. Eumo i Diputació de Barcelona, 1986. Sobre este libro escribí "Pedagogía y vida. Posibles sugerencias para México de la filosofía de la educación de Joaquín Xirau”, en Omnia. 
indeleble. También en Gabriela, según pude constatar en las tres partes de su libro, donde se nos ofrece su "interpretación muy viva y muy personal" (p. VII) de la fenomenología de la conciencia amorosa, aportando, además, muchos datos biográficos y bibliohemerográficos de Xirau i Palau.

La cosmovisión hospitalaria de Joaquín Xirau, a mi juicio, también anuncia, junto a otros filósofos contemporáneos suyos, el nuevo paradigma científico, a saber, el sistémico u holista, es decir, orgánico, que ya había barruntado Aristóteles. La realidad se enfoca como un conjunto de elementos relacionados de manera tal, que si se altera una parte se altera el todo. Este enfoque supone que cada holon es discernible de otros, y que sus partes también son discernibles. También cada holon puede ser estudiado en su unicidad.

El sistema de los seres vivos no se deja someter a leyes. La biología y la historia señalaron un ámbito de la realidad irrepetible, cambiante, que evoluciona al azar, es decir, que deshace el método nomológico, aplicable a un mundo autómata, repetitivo para mostrarlo transitorio, creador y sorprendente o impredictible. Un antecedente de este paradigma lo encontró Xirau i Palau en Ramón Llull. El último, definió los vivientes como estructura, fuerza creadora y organización arquitectónica.

Para este paradigma tampoco existe el observador neutral, sino el participante u observador relativista. Dicho con Hernández García, el conocimiento es ciencia, y la ciencia es producto del espíritu, no un reflejo indiferente de la realidad; luego, el mundo aparece "como un correlato del sujeto" y el sujeto del mundo (p. 179). No se trata, empero, de un relativismo fácil que, al modo del canto de las sirenas, se atreve a interpretar cualquier cosa, sino que hay coincidencias interpretativas y reglas para la observación. Lo destacable es que el mundo es parte de mí porque estoy, con otros, en el mundo. En unas cuantas palabras, ni el objetivismo hueco de que hablaba el paradigma nomológico ni la relativización que desemboca en la autarquía tienen el espíritu de fineza, en frase de Pascal, que requiere el conocimiento o episteme. Adicionalmente, el conocimiento ya no se considera fruto exclusivo de la razón, sino que depende de una serie de intereses empapados de afectos.

Joaquín Xirau emprendió una exaltación de la vida y su capacidad creativa o poiética. Y concretamente de la autonomía de la vida humana que depende de valores. Gracias a éstos vale la pena vivirla. A su vez, señala Gabriela, los valores, incluyendo el de verdad y falsedad, es decir, el conocimiento, nacen del amor. La hipótesis básica de La plenitud vital es que la conciencia amorosa es el centro alrededor del cual gravitan las aportaciones de Xirau i Palau. Teniendo a la vista la crisis ética y existencial de la época contemporánea, este filósofo se

Revista de la Dirección General de la División de Estudios de Posgrado. México, unam, año 5, núm. 17, diciembre, 1989 , pp. 53-59. 
abocó a la tarea de construir, siguiendo el ejemplo de san Agustín, un ordo amoris, un cimiento que ordene este caos en un cosmos justo, vital, amable.

El amor no es un valor ni un logoi, sino que genera valores y conocimientos, así como toda suerte de experiencias no sólo éticas, sino también estéticas. Para darnos a conocer este impulso, Joaquín Xirau abrevó en dos fuentes: la griega, especialmente en Platón, y en el cristianismo.

Para los griegos el amor es locura, entendida no como enfermedad, según interpreta Gabriela Hernández (p. 111), sino como una manía o un frenesí positivos. El Eros terrenal, dijeron, es voluptuosidad que aspira a la satisfacción. La obtiene momentáneamente y reemprende la carrera en busca de lo que considera la belleza, o sea, de Venus (edípico es el asunto). Bajo la influencia de mitos y ritos indios, celtas e iraníes, los órficos concibieron esta libido como angustiosa y el cuerpo como una cadena, según la alegoría de la caverna que expone Platón, o sea como la cárcel del alma. En el Fedón este mismo autor supone que la filosofía llega cuando se está ya muerto y, asimismo, hace morir, frases que reproduce Gabriela (p. 114), porque la producción intelectual supone matar las jugarretas del travieso Eros terrenal. Sin embargo, la pulsión es entrega. En aquel inmortal ágape o El banquete, Aristófanes habló del amor como la tendencia a unirse con la otra mitad, a regresar al andrógino primigenio; ahora bien, si se amalgamaran las dos realidades complementarias dejarían de amar. Esto no es ni debe ser así. El Eros terreno es, pues, limitado y su limitación lo hace necesario. En mi interpretación, que no coincide con la de esta filósofa, para Xirau i Palau el cuerpo es un identificador de la persona y, además, por la libido, aunque no sólo por ésta, es expansivo y creador. Adicionalmente, este centro siente, piensa y aspira. Quien se ama a sí, y sólo quien se ama a sí es capaz de amar a los otros, ama a su cuerpo. Por lo tanto, creo que frente a la exigencia platónica de alcanzar una vida que ya no es vida, Joaquín Xirau ensalzó el cuerpo. También la Biblia en tanto habla de su resurrección.

El Sócrates inventado por Platón adoró al Eros celestial que, anhelante y entusiasmado, se dirige a lo excelso, a lo celestial, a las esencias que subsisten. La ruta ascensional depende del afán de arribar al Sumo Bien, que también es verdad y belleza, esto es, valores. Posiblemente el discurso de El banquete que más convenció a Xirau i Palau es el de Diótima, más abarcante, más general. Eros, dice, es hijo de Poros, la riqueza y de Penia, la carencia. Es rico y pobre. Es actividad llena, sin pausa inútil. Es delirante. Es movimiento que, reconociendo que no posee nada, o casi nada, aspira a llenar sus faltas, sea el caso la sabiduría: no hay amor soberbio. Tampoco exclusivamente narcisista. Esta manía, búsqueda entusiasmada del cuerpo que complementa, también busca el complemento afectivo e intelectual. Eros facilita el diálogo de quien quiere saber y reconoce su ignorancia. En su movimiento se inclina al saber; 
es la aspiración que abre el camino al logos, o, si se prefiere, es su condición de posibilidad, capaz inclusive de encontrar el carácter uno y único de cada holon. Este deseo en busca de la plenitud, explica Hernández García, es rapto, delirio de completarse. Notemos que sólo el ego autocentrado es capaz de ir en pos del intercambio. Por amor se leen los libros y se escuchan discursos. Por amor se concuerda y discrepa.

Por amor han nacido los valores compartidos y construidos intersubjetivamente. En este sentido, Gabriela reproduce unas oraciones de Lo fugaz y lo eterno de Xirau i Palau. Las parafraseo: vivir es trascenderse y buscar en el mundo aquello que haga a la vida digna de vivirse (p. 103). La vida humana es plena si se llena de valores, de los cuales nacen las utopías, las ilusiones, la esperanza de un mañana mejor. Cierto que hablamos de los valores en positivo y negativo: bueno/malo; bello/feo; justo/injusto, aunque los segundos son eso, negativos o carencia del valor positivo, que Gabriela llama antivalores que cierran o desvían el espacio de la comunidad y el utópico comunitarismo.

Los valores no son entes o cosas. No existirían sin sujetos que los aprehendan y propongan. Por amor se ilumina el mundo desde su lente, es decir, desde los ideales. Y si damos este paso del valor al ideal, es porque el primero se llena de contenido en tanto el amor los lanza al porvenir, al presente del futuro. Por amor luchamos por las generaciones que habrán de sucedernos, $o$ sea que orienta la vida, la plenitud vital, en expresión de Xirau i Palau que recoge y hace suya Hernández García (p. 93). Además, el amor ordena jerárquicamente la realidad según tales valores.

Quien es fiel a sus ideales más caros forja su dignidad. En este punto ya hemos entrado en la charitas o amor caritativo, fuente de la vida auténtica, porque "cualquier valor es valor vital" (p. 101). La caridad es riqueza que se pone en contacto con las esferas más altas de la moral que, lanzada al futuro, pone en acto la creatividad.

San Agustín, Ramón Llull y Pascal, entre otros, pensaron un Dios amor. Bondad suprema sin resquicios de maldad. En el cristianismo, el Ser Supremo dejó de ser el impasible motor inmóvil aristotélico, dicen Joaquín Xirau y Gabriela Hernández. Fue concebido como magnanimidad, concepto que remite al punto de encuentro entre la ética y la estética porque se define como lo bello-bueno (o kalokagathía se lee en la Ética a Nicómaco), y esto es decir bondad suprema, abundancia amorosa que se derrama, se expande, desborda. Por lo mismo, es gracia o espontaneidad que enamora y creatividad sin límites. Éste es el significado que atribuyen los mentores de Xirau i Palau y él mismo a las palabras del Evangelio de San Juan que definen a Dios como caridad.

El Dios personificado del cristianismo nos ha dado un privilegio a los humanos, a saber, la libertad. En tanto es omnipotente, es el único que quiere lo que puede y puede lo que quiere. Quiso darnos la libertad que también elige 
entre el bien y el mal, entre la sociabilidad y la insociabilidad, entre la justicia y la injusticia. Podría saber qué haremos, pero no quiere saberlo. Dejó a nuestra potestad la evolución, la historia irreversible: quiso que le fuéramos informativos. También nos dejó el ejemplo y el Verbo. Seguir la ruta de entrega, la igualdad, la justicia distributiva y retributiva, es seguirlo.

Dios, bueno por excelencia, confía en nuestro lado bueno, y nos insta a tener fe y esperanza en la potencial bondad de nuestro congéneres. La conclusión de la antropología filosófica que propone Joaquín Xirau y registra Gabriela, es la siguiente: existe la propuesta de que tenemos, dentro de las diferencias, una semejanza análoga con Dios. En tanto caridad, el amor "es analógico en el ser divino y el ser humano" (p. 123).

Una bella persona, medida con el patrón de la magnanimidad divina y en el entendido de que únicamente somos su sombra que frecuentemente desfallece y es infiel a su parte buena, es caracterizada por Xirau i Palau, en interpretación de Hernández García, por su volumen o riqueza de sentimientos e ideas que se proyectan hacia el mañana. La magnanimidad no está tanto dada cuanto es trabajada. Esto es, para llegar a ser caritativo hay que esculpirse, ir afinándose hasta que la reacción bondadosa y solidaria, en bien del otro y de la comunidad, ocurra espontáneamente, con gracia.

El caritativo trata al otro como fin y no sólo como medio, y esto significa también que no espera recompensa o reciprocidad. Obedece a este imperativo no por deber, como proponía Kant. No se trata de imponernos actuar en contra de nuestra naturaleza mala, sino de alcanzar la sana y desborda vitalidad, actuar bien sin pensar, como manía, delirio anormal, como desbordamiento. Tampoco el amor caritativo es solidario por compasión, que ubica al agente en una situación de superioridad respecto al destinatario de su acto. Me pregunto, ¿en esta parte no se escuchan en Xirau i Palau los ecos de Schiller?

En la medida en que nos autoesculpimos en dirección a la magnanimidad, la caridad va acrecentando la estima de sí: no habrá un movimiento centrífugo hacia el otro donde se carece de otro centrípeto. Y esto implica que el caritativo es una personalidad fuerte, luchadora.

Este ir hacia los demás y orientarse hacia el futuro, hacia la esperanza y la fe, impulsada por la caridad, vuelve a la persona un ser creativo en su "plenitud espiritual, proyección ideal y renovación vital” (p. 148). También la hace clarividente. No es ciega a las injusticias, a la maldad, a los contravalores puestos en práctica.

Sin caridad el mundo es indiferente. En contrario, el amor nos perfila como un "ser por referencia" (p. 156), nuestra estancia en el mundo es un "estar con", en copresencia solidaria. Todo nos afecta, todo nos importa, todo nos concierne. Nada deja de estar fuera de nuestras preocupaciones. No le 
faltó razón a san Francisco de Asís. Diré como apostilla: el lobo es nuestro hermano lobo porque juega un papel armonizador en un ecosistema. Antecediendo el concepto de Heidegger de cuidado o cura (Sorge), Joaquín Xirau agrega que la raíz de esta preocupación es la charitas, de seguirla nace el deseo de recomponer el mundo. Otra virtud del amor es que no disuelve ni funde: nadie que ama puede suprimir al otro ni a sí mismo.

El malo confunde medios y fines, impone, niega las diferencias culturales y afirma la desigualdad económica. Está lleno de la pleonexía de que habló Aristóteles: quiere todo para sí; odia, utiliza al otro congénere como instrumento. Y mal vive porque recela, espera lo peor del otro. Sin embargo, la caridad de una bella persona no garantiza su felicidad. Y esto lo dijo magistralmente don Quijote, el loco cuerdo: la virtud es más odiada por lo malos que amada por los buenos. ${ }^{3}$

En suma, en tanto incompletos, limitados, falibles, hemos de juntar a Eros con la iluminación de charitas que nos dota de gracia y dignidad, características de la belleza moral.

Una observación. Si el odio es el contraconcepto del amor, su negativo, la solidaridad y el sentido de justicia nacen de un sentimiento de rechazo por lo injusto. Si no por un odio, sí por un desagrado y un fuerte coraje que motiva al caritativo a que, por ejemplo, eche a los mercaderes del templo y enfrente a sus grandes sacerdotes. No faltará un Caifás que lo combata y entregue al enemigo. Esta rabia es consustancial al amor, forma parte de este volumen de afectos que le son propios.

Termino manifestando mi beneplácito de que exista Plenitud vital, de Gabriela Hernández García, quien me obligó a releer a Joaquín Xirau i Palau. Espero haber despertado el interés de algunos de sus potenciales lectores. Ambos filósofos saben despertarnos del sueño para abrirnos las puertas a una vida bajo el cobijo del amor. Permítanme aplicarles esta aliteración de Ramón Llull: "Amado, en la prisión del amor nos tienes enamorados con tus amores". ${ }^{4}$

${ }^{3}$ Miguel de Cervantes Saavedra, El ingenioso hidalgo don Quijote de la Mancha. Ed. de John Jay Allen. 1a. reimp. México, Rei, 1944. (Letras hispánicas) vol. I, cap. XLVII, p. 550 .

${ }^{4}$ Joaquín Xirau, Obras, p. 173. 